\section{Physicochemical and Histological Changes in the Arterial Wall of Nonhuman Primates during Progression and Regression of Atherosclerosis}

\author{
Donald M. Small, M. Gene Bond, David Waugh, \\ Margaret Prack, and Janet K. Sawyer \\ Biophysics Institute, Departments of Medicine and Biochemistry, \\ Boston University School of Medicine, Boston, Massachusetts \\ 02118; Department of Comparative Medicine, Bowman Gray \\ School of Medicine, Wake Forest University, Winston-Salem, \\ North Carolina 27103
}

bstract. To identify the temporal changes occurring during progression and regression of atherosclerosis in nonhuman primates, we have studied the physicochemical and histological characteristics of arterial wall lesions during a 30-mo progression period of diet-induced hypercholesterolemia and during a 12-mo period of regression. Three groups of cynomolgous monkeys ( $\mathrm{Ma}$ caca fascicularis) were studied. Control groups were fed a basal chow diet for 18,24 , and 30 mo and were compared with progression groups that were fed a high-cholesterol-containing diet for up to $30 \mathrm{mo}$. Regression groups were fed a high-cholesterol diet for $18 \mathrm{mo}$ to induce atherosclerosis and then fed monkey chow for up to 12 mo. The progression group monkeys were killed at 6,12 , 18,24 , and $30 \mathrm{mo}$, and the regression animals were killed at 24 and 30 mo (i.e., after 6 and 12 mo of being fed a noncholesterol-containing chow diet). Histology and morphometry, physical microscopy for cholesterol monohydrate crystals, foam cell and droplet melting points and chemical composition studies were completed on a large number of individual arterial lesions. Control animals had very little cholesterol ester, rare foam cells, and no extracellular cholesterol ester droplets or choles-

This work was presented in part at the 1982 American Heart Association Meeting, Dallas, TX, November 1982, and published in abstract form: Small, D. M., D. Waugh, M. Prack, and M. G. Bond, Circulation, 66(Part II):II-225/900a.

Address reprint requests to Dr. Small, Boston University School of Medicine.

Received for publication 6 September 1983 and in revised form 30 January 1984.

J. Clin. Invest.

(c) The American Society for Clinical Investigation, Inc.

$0021-9738 / 84 / 06 / 1590 / 16 \$ \$ 1.00$

Volume 73, June 1984, 1590-1605 terol crystals. During progression, the arteries first increased cholesterol ester content to produce high melting $\left(\sim 45^{\circ} \mathrm{C}\right)$ foam cell-rich lesions essentially devoid of cholesterol crystals. With time, the number of cholesterol crystals increased so that by 30 mo large numbers were present. Foam cells decreased with time but their melting temperature remained high while that of extracellular droplets fell to $\sim 38^{\circ} \mathrm{C}$. Between 18 and 30 mo necrosis appeared and worsened.

After 6-mo regression, unexpected changes occurred in the lesions. Compared with 24-mo progression, the chemical composition showed a relative increase in free cholesterol, a decrease in cholesterol ester and microscopy revealed large numbers of cholesterol crystals. Concomitantly, foam cells decreased and the melting temperature of both intra- and extracellular cholesterol ester markedly decreased. After 12-mo regression cholesterol decreased, cholesterol crystals and necrosis diminished and collagen appeared increased.

Thus, during progression there is initially an increase in the number of foam cells containing very high-melting intracellular cholesterol ester droplets. By $30 \mathrm{mo}$, cholesterol crystals and necrosis dominate and high-melting foam cells appear only at lesion margins, suggesting that the initial process continues at the lesion edge. The lower melting point of extracellular esters indicates a lipid composition different from intracellular droplets. Thus, the changes observed in these animals generally reflect those predicted for progression of human atherosclerosis.

During the initial 6 mo of regression, necrosis remains, the number of foam cells decreases, and cholesterol ester content decreases; however the relative proportion of free cholesterol content increases, and large numbers of cholesterol crystals are formed. Thus, large and rapid decreases in serum cholesterol concentration to produce 
regression in fact may result in the precipitation of cholesterol monohydrate and an apparent worsening of the lesions. More prolonged regression (12-mo) tends to return the lipid composition of the artery wall towards normal, partially reduces cholesterol crystals, and results in an improved but scarred intima.

\section{Introduction}

Human atherosclerosis is a disease that affects the arterial wall where the intima progressively thickens, which is due in part to the accumulation of lipids and connective tissue. These thickened areas, plaques, may ultimately result in a decrease in blood flow with ischemia of tissue that is supplied by the affected vessel. A variety of human lesions have been identified from the small, slightly raised, yellow fatty streak to the advanced calcified plaques (1). Although some controversy exists, the presence of lesions with intermediate histological and biochemical characteristics between fatty streaks and atherosclerotic plaques suggests that the development of at least some of the more advanced plaques is through fatty streak/intermediate lesion precursors $(2,3)$. The physicochemical characteristics of normal human intima (4), fatty streaks $(3,5-7)$, intermediate lesions (3), and atheromatous plaques have been carefully defined $(3,7,8)$. Atherosclerotic lesions appear to progress through the sequential separation and deposition of lipid phases in the arterial intima. Most of the lipids in the normal intima in children are phospholipids and thus the composition of their intima lies on the right-hand side of the triangular coordinate plot (Fig. 1). The intima gradually accumulates lipid with age $(4,9)$, and Katz (4) has shown that the composition moves down a line extending from the composition at infancy toward the composition of low density lipoproteins (LDL). This lipid is extracellular $(4,9)$ and can be accounted for by the gradual deposition of lipid with compositions similar to those of LDL. The studies of Hoff et al. (10) and Hollander et al. (11) suggest that this accumulation may be due to the deposition of slightly altered or denatured LDL. Katz (4) has shown that in the fifth decade of life the normal arterial composition changes and becomes richer in free cholesterol, which suggests a biochemical change in the lipid composition. Fatty streak lesions contain relatively more cholesterol ester than LDL, and are rich in cholesterol oleate; thus, these lesions presumably process lipoproteins and store intracellular ester rich in oleic acid (3). The composition of fatty streaks does not simply reflect deposition of LDL, but rather a lesion that processes and stores lipids of uncertain origin within foam cells (12).

The lipids of normal intima and fatty streaks occur in the two-phase region, indicating that the lipids are separated into a cholesterol ester-rich phase and a phospholipid-rich phase. In fatty streaks, the cholesterol ester phase is present largely within cells as small cytoplasmic emulsion droplets $(3,5-7)$. Inter-

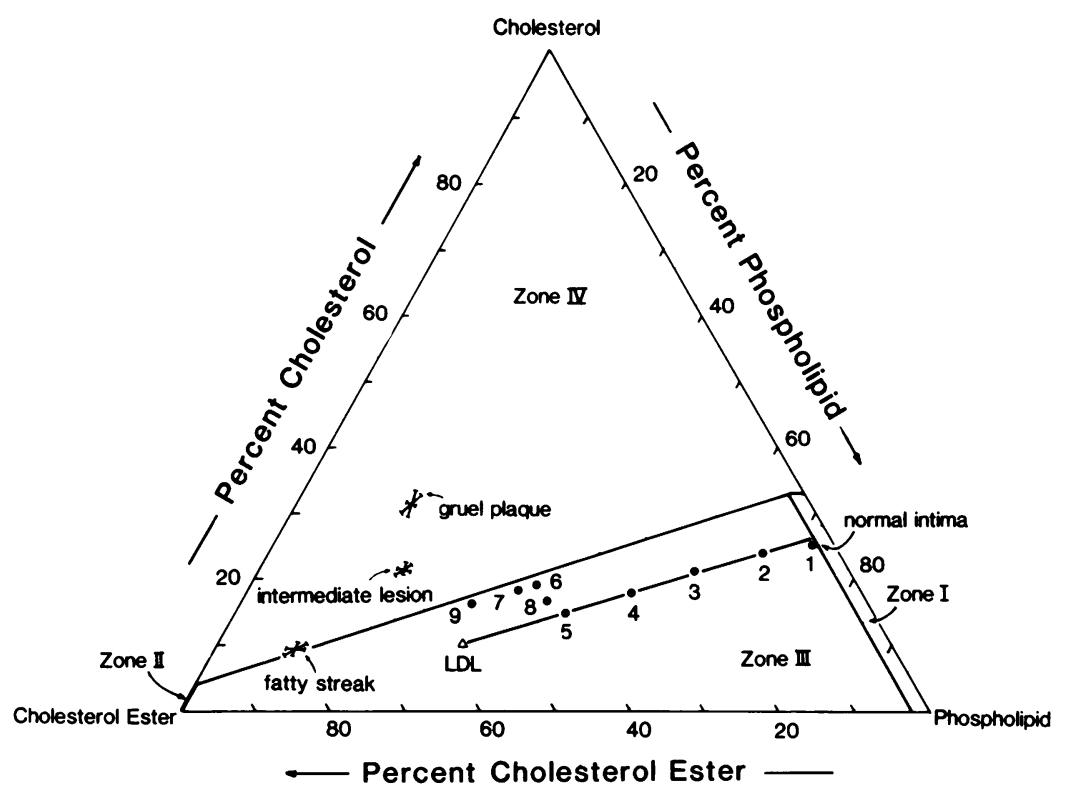
LDL are added to the arterial intima during the first four decades of life. In the fifth dicating that lipids with a composition very similar to normal free cholesterol and deviate from the newborn-LDL line (4). The composition of human fatty streaks, intermediate lesions, and gruel plaques are plotted as the mean \pm 1 SEM for each component (from reference 3). Fatty streaks have a composition that can be described as two phases: a large amount of a cholesterol ester-rich phase and a phospholipid phase, whereas intermediate lesions and gruel plaques contain excess free cholesterol and should contain cholesterol monohydrate crystals.

Figure 1. Phase diagram of the major lipids of the arterial wall. The phase diagram phospholipid/cholesterol/cholesterol ester is an equilateral triangle giving the weight percentage of each lipid. There are four major zones (7). Zone I is a single phase made up of phospholipid bilayers that contain cholesterol and small amounts of cholesterol ester. Zone II is a cholesterol ester phase containing 0-5\% cholesterol but no phospholipid. Zone III is a two-phase region consisting of both the cholesterol ester phase and the bilayered phospholipid phase. Zone IV is a three-phase region in which the third phase formed is cholesterol monohydrate crystals. The numbered points are the compositions of normal intima of newborns (point 1) and subjects of increasing age: 2 $=$ first decade, $3=$ second decade, $\ldots, 9=8$ th decade (taken from Katz [4]). The compositional data indicate that newborns have all of their lipids in the single phase, the phospholipid phase, whereas the normal intima of humans up to the fifth decade fall in the two-phase region and have increasing amounts of the cholesterol ester-rich phase. Through the fourth decade (point 5) the lipid comal

(1)


mediate lesions appear grossly like fatty streaks, although perhaps slightly larger, but their composition is different (3). They have more free cholesterol and are in an intermediate position between the composition of atheromatous plaque and a fatty streak (Fig. 1). The content of sphingomyelin, lysolecithin, and the composition of cholesterol ester fatty acids also is intermediate between plaques and fatty streaks (3). However, only a minority of these lesions have identifiable cholesterol monohydrate crystals and these crystals are small and few in number, which indicates that most of the free cholesterol is held in a supersaturated state (3). Atheromatous plaques have compositions richer in free cholesterol, but importantly, the central region of an atheromatous plaque is largely necrotic, and is composed of extracellular lipids and cellular debris. A variety of biochemical disorders could combine to create intermediate lesions and atheromatous plaques from fatty streaks, and these have been discussed (12).

A problem arises in using static autopsy material to document the natural history of atherosclerosis progression. Most simply stated, we do not know the absolute time course, nor the specific history of individual lesions, which are observed at a single time point, i.e., at autopsy or in surgical specimens, and therefore one must suggest that larger and more complicated lesions are older. Clearly, plaques are larger than fatty streaks and intermediate lesions and thus the sequence of fatty streaks to plaques has been imputed.

A purpose of the present study was to determine the physicochemical and histological characteristics of lesions developing in nonhuman primates over a period of $30 \mathrm{mo}$ and, further, to examine the effects of reducing serum cholesterol concentration over a 12-mo period in animals in which atherosclerosis had been induced for $18 \mathrm{mo}$. The results support the concept that foam cell lesions (fatty streaklike lesions) are precursors to cholesterol-monohydrate crystal-containing plaques. "Regression" that was induced by diet in which serum cholesterol was lowered toward normal produced a somewhat unexpected change in the lesion's physical chemistry and histology. The findings suggest that drastic lowering of serum cholesterol to achieve regression may worsen the lesions during the first $6 \mathrm{mo}$, and that only after longer periods of normocholesterolemia does the arterial wall begin to return towards normal.

\section{Methods}

Animal model. The adult male cynomologous macaques (Macaca fascicularis) used in this study were imported from Malaya, and were part of an initial colony of 98 animals. After a quarantine period of $90 \mathrm{~d}$, and without conscious bias, 18 animals were selected and assigned to one of three control groups. The remaining 80 animals were fed for 5 wk a cholesterol challenge diet that contained $0.3 \mathrm{mg}$ cholesterol $/ \mathrm{kcal}$ with $\sim 40 \%$ of calories from lard. Total serum cholesterol concentrations were measured after the animals had consumed this diet for 4 and 5 wk, and the values from these two samplings were averaged for each animal. The resulting means were rank ordered, and the top and bottom 10 animals from the distribution were removed for other studies. The remaining 60 animals were divided as follows: five progression groups ( $n=8 /$ group), which were fed an atherogenic diet (Table I) for either $6,12,18,24$, or $30 \mathrm{mo}$, and then killed for evaluation of atherosclerosis; two regression groups ( $n=10 /$ group), which were fed the same atherogenic diet for $18 \mathrm{mo}$ but then changed to monkey chow diet for either 6 or $12 \mathrm{mo}$, after which the animals were killed. The assignment of animals to specific progression and regression groups was done with

Table I. Composition of Atherogenic Diet

\begin{tabular}{|c|c|c|c|c|c|c|}
\hline Ingredients & Grams & Protein & Fat & Carbohydrate & $\mathrm{cal} / 100 \mathrm{~g}$ & Cholesterol \\
\hline & $g / 100 \mathrm{~g}$ & $g$ & $g$ & $g$ & & $m g$ \\
\hline Casein & 9.00 & 9.0 & - & - & 40.5 & - \\
\hline Lactalbumin & 8.0 & 8.0 & - & - & 36.0 & - \\
\hline Wheat flour & 33.50 & 3.51 & 0.335 & 25.49 & 120.78 & - \\
\hline Dextrin & 10.0 & - & - & 10.00 & 40.00 & - \\
\hline Sucrose & 3.6 & - & - & 3.6 & 14.4 & - \\
\hline Butter & 23.50 & 0.1 & 19.0 & 0.1 & 171.85 & 70.5 \\
\hline Alphacel & 5.5 & -- & - & - & - & - \\
\hline Applesauce & 0.7 & 0.003 & trace & 0.168 & 0.68 & - \\
\hline Hegsted's salts mixture & 3.8 & $\ldots$ & - & - & - & - \\
\hline Vitamin mixture (No vitamin D) & 20 & - & - & 2.0 & 8.0 & - \\
\hline Cholesterol & 0.3599 & - & 一 & - & - & $359.9^{*}$ \\
\hline
\end{tabular}

* Equivalent to $1.00 \mathrm{mg}$ cholesterol/cal. $¥$ Protein $\cong 22 \%$ of calories. $§$ Fat $\cong 40 \%$ of calories. "Carbohydrate $\cong 38 \%$ of calories. $\uparrow$ Vitamin $\mathrm{D}_{3}$ was added in a small amount of corn oil. 
the conscious bias of equalizing mean serum cholesterol concentrations among the groups.

Necropsy procedure. At 8:00 a.m. the animals were taken for radiographic and ultrasound studies, which will be reported separately. The animals were put to sleep with pentobarbitol, exsanguinated, and the cardiovascular system was perfused with saline at room temperature $\left(20-24^{\circ} \mathrm{C}\right)$. Certain arteries were pressure-fixed at mean arterial pressure to maintain a normal architecture. Autopsies were performed on animals within $15 \mathrm{~min}$ of death, and the abdominal and thoracic cavities were opened. The aorta and right external iliac were immediately dissected free and a photograph or drawing was made of the surface characteristics.

Physicochemical studies. Tissue blocks for physicochemical studies were taken from representative lesions and immediately dissected by using a $\times 20$ binocular microscope with a temperature-controlled stage at $\sim 30^{\circ} \mathrm{C}$. The intima was stripped as free as possible from the underlying media and adventitia and was then bisected and half placed in chloroform/ methanol $(2: 1, \mathrm{vol} / \mathrm{vol})$ for chemical determination of lipid composition. The composition of the dissected intima and its underlying media were measured in a few cases to compare their compositions. The other half was transferred under $20-40 \times$ onto a microscopic slide and orientated to give an en face view of the intima. If the intima was thick, then several slides were made by teasing the medial side of the intima onto the slide until the intima was thin enough to be observed en face. Highly calcified regions, which could not be teased or crushed onto the microscopic slide, were dissected and removed. Such lesions only occurred with some frequency in the progression animals at $30 \mathrm{mo}$ or in the regression animals. Each intimal lesion was examined on the hot-stage polarizing microscope (13). For each lesion, 10 low-power fields were observed from each slide. If the lesion required more than 1 slide, 10 low-power fields were observed from each slide and the average of all slides was taken. The following semiquantitative estimates were made.

(a) The number and size of cholesterol monohydrate crystals was assessed by counting the number of crystals in 10 low-power fields. The size of the crystals was measured with an optical micrometer in the eyepiece. The crystals were identified by their edge angle, $79.6^{\circ}$, birefringence, and melting characteristics, as previously described $(3,14)$. The data were expressed as the number of crystals per 10 low-power fields, as follows: none in the entire lesion, $<10,10-20$, and $>20$. The data, although semiquantitative, allow a reasonable estimate of the size and number of crystals in individual lesions.

(b) The number of foam cells was estimated by counting the number of cells in the en face intimal preparation. Since cells often tended to be clumped in groups, only a qualitative estimate of the number of cells per lesion could be made, and this is expressed as "many," which means large clumps of foam cells in several fields; "few," one had to search through several fields to find a few foam cells; or "none," meaning that no foam cells were seen in at least 10 low-power fields.

(c) The number of extracellular droplets was counted in a way similar to the crystals. In all lesions from animals in the progression groups these droplets were numerous. Virtually no droplets were seen in arteries from the control groups, and almost none were seen in the arteries of the 12-mo regression group.

(d) The melting point of the intracellular and extracellular cholesterol ester droplets was determined by observing cells using crossed polarizers while raising the temperature at $1^{\circ} \mathrm{C} / \mathrm{min}$ and noting the final melting point-that is, the temperature at which all cholesterol ester droplets within the cell become isotropic $(13,15)$. Each cell was identified by noting its nucleus in the cytoplasm. Since cholesterol esters within a given foam cell melt over a narrow range, $2-4^{\circ} \mathrm{C}$, the endpoint of melting was taken as the cell-melting temperature. In each lesion the melting points of at least 10 individual cells were determined and the mean and standard deviation of the melting temperature for that lesion was calculated. The data are expressed as follows: the mean and standard deviation of melting for each lesion is ranked from lowest to highest and plotted in cumulative fashion-that is, plotted as the percent lesions melted as a function of temperature. Thus, it is possible to measure the temperature at which $50 \%$ of the lesions are in the melted state, and to relate this to body temperature. A series of curves is generated for each group of animals. Individual extracellular droplet melting was measured in a similar fashion. Droplets and cells from the same groups of animals were compared to see whether the melting transitions were different for extracellular droplets and intercellular droplets.

Histological evaluation. Tissue blocks for qualitative and quantitative evaluation of atherosclerosis severity were taken from areas adjacent to those selected for physicochemical evaluation, and also from five standard sites equal distances from each other in the thoracic aorta. Cross-sectional tissue blocks were immersion-fixed in $10 \%$ neutral buffered formalin, dehydrated through increasing concentrations of ethanol, and embedded in paraffin. Two microscopic sections, each measuring $\sim 6 \mu \mathrm{m}$ in thickness, were cut and stained with hematoxylin and eosin and with Verhoeff van Gieson stain.

Microscopic slides from each arterial site were evaluated morphometrically by projecting the histological image on the active surface of a Graf Pen digitizer, and measuring cross-sectional areas of the tunica intima and media (16). Intimal area/medial area ratio was then calculated. Intimal area was defined as that tissue between the endothelial layer and the innermost elastic lamina. The tunica media was defined to include all tissue between the innermost and external elastic laminae. Intimal area, with certain assumptions, represents a measure of atherosclerosis per se in this hypercholesterolemic animal model (16). Intimal area/medial area ratio is a term used to describe lesion severity normalized for arterial size (16). Maximum intimal thickness was measured directly from the projected specimen.

The section of tissue adjacent to that taken for histological and physicochemical studies was extracted by the method of Folch et al. (17), dried, taken up in $\mathrm{CHCl}_{3}$, and run on quantitative thin-layer chromatography plates by the method of Downing (18) as modified by Katz et al. (3) for arterial intima. The phospholipids were summed and the chemical results expressed as the weight percent of cholesterol esters plus free cholesterol plus phospholipids and plotted on triangular coordinates $(3,7)$ according to the method described earlier $(19)$.

\section{Results}

The results will be discussed under the headings of progression and regression. The control groups for the progression study were chow-fed animals killed at 18, 24, and 30 mo. Regression groups will be compared with the control chow-fed animals as a base line. Further, the animals at 24-mo progression will be compared with the 6-mo regression group, since both groups of animals were killed after 24 mo in this study-one had 18 mo of progression and 6 mo of regression and the other had 24 mo of progression. The 24-mo progression group had 6 mo more of the cholesterol-rich diet than the regression groups.

\section{Animal colony}

During the course of the experiment nine animals died. These deaths occurred primarily because of infectious diseases and 


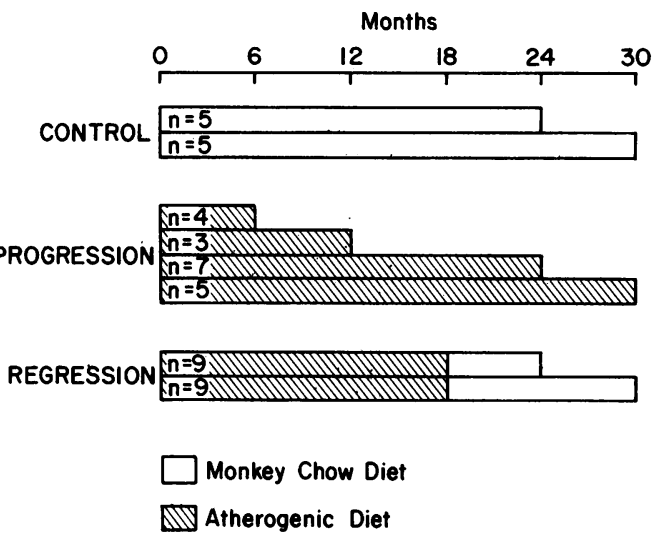

Figure 2. Distribution of animals among groups studied physicochemically.

were distributed among the groups as follows: 30-mo progression, three animals; 6-, 12-, and 24-mo progression, one animal in each group; and one animal from each of the three control groups. Thus, at necropsy 15 animals remained in the control groups and 51 in the experimental groups. Although the arteries of all these animals were examined histologically, detailed physicochemical studies were carried out on only 10 controls and 37 experimental animals. The number and distribution of animals within groups that were evaluated for physicochemical studies is shown in Fig. 2.

The clinical characteristics of the animal colony during the experiment are presented in Table II. Feeding the atherogenic diet during the progression phases resulted in a high level of hypercholesterolemia (range of means for the various groups was $681-837 \mathrm{mg} / \mathrm{dl}$ ). Control groups fed a basal chow diet had mean serum cholesterol concentrations of $\sim 120 \mathrm{mg} / \mathrm{dl}$. The regression groups also developed a marked hypercholesterolemia during the 18-mo progression phase and most of the cholesterol is carried in large high melting high density lipoproteins (20). However, when these animals were then fed the nonatherogenic chow diet, serum cholesterol concentrations fell $<200 \mathrm{mg} / \mathrm{dl}$ by 4 mo and were nearly normal by the end of the regression periods (Table II). Body weights for the animals in each group are also presented in Table II. All animals were of adult age at the beginning of the experiment, and therefore relatively little change in body weight was observed when comparing initial

Table II. Clinical Characteristics of Animal Colony (M. Fascularis)

\begin{tabular}{|c|c|c|c|c|}
\hline & \multicolumn{2}{|c|}{ Total serum cholesterol concentration } & \multicolumn{2}{|l|}{ Body weight } \\
\hline & Progression & Regression & Initial & Terminal \\
\hline & $m g / d l$ & & $k g$ & $k g$ \\
\hline \multicolumn{5}{|l|}{ Progression } \\
\hline 6-mo & $708 \pm 127(7)^{*}$ & & $4.55 \pm 0.40$ & $4.85 \pm 0.43$ \\
\hline 12-mo & $733 \pm 183(7)$ & & $5.09 \pm 0.76$ & $6.12 \pm 1.53$ \\
\hline 18-mo & $736 \pm 169(8)$ & & $5.12 \pm 0.65$ & $4.97 \pm 0.65$ \\
\hline 24-mo & $681 \pm 99$ & & $5.28 \pm 0.42$ & $4.97 \pm 0.52$ \\
\hline 30-mo & $709 \pm 145(5)$ & & $4.73 \pm 0.31$ & $4.71 \pm 0.40$ \\
\hline \multicolumn{5}{|l|}{ Regression } \\
\hline 18-mo progression followed by & $837 \pm 199(9) \ddagger$ & & $4.27 \pm 0.80$ & $5.07 \pm 0.71$ \\
\hline 2-mo regression & & $297 \pm 126(9) \ddagger$ & & \\
\hline 4-mo regression & & $168 \pm 55 \quad(9) \neq$ & & \\
\hline 6-mo regression & & $153 \pm 52 \quad(9) \ddagger$ & & \\
\hline 18-mo progression followed by & $713 \pm 132(9) \ddagger$ & & $4.14 \pm 0.44$ & $4.88 \pm 0.47$ \\
\hline 2-mo regression & & $223 \pm 86 \quad(9) \ddagger$ & & \\
\hline 4-mo regression & & $166 \pm 67$ & & \\
\hline 12-mo regression & & $127 \pm 27 \quad(9) \ddagger$ & & \\
\hline \multicolumn{5}{|l|}{ Control } \\
\hline 18-mo & $121 \pm 3$ & & $4.34 \pm 0.49$ & $5.31 \pm 0.66$ \\
\hline 24-mo & $118 \pm 9$ & & $4.24 \pm 0.73$ & $4.84 \pm 0.46$ \\
\hline 30-mo & $121 \pm 16 \quad(5)$ & & $4.23 \pm 0.51$ & $4.78 \pm 0.24$ \\
\hline
\end{tabular}

* All values expressed as mean \pm standard deviation. The numbers in parentheses are the numbers of animals. $¥$ These values are for the same animals. The progression value is after $18 \mathrm{mo}$ of a high cholesterol diet and the subsequent regression values are of the $2,4,6$, or $12 \mathrm{mo}$ of a low cholesterol diet. The values after 18-mo progression are not significantly different nor are the values at 6 and 12 mo of regression ( $t$ test). 
with terminal measurements. Increases in body weights between these two observations exceeded $1.0 \mathrm{~kg}$ in only two of the groups, i.e., 12-mo progression and 18-mo control.

\section{Progression of atherosclerosis}

QuAlitative EVAluation. Control. The thoracic aorta from the 18- and 24-mo control animals were similar in histological appearance and will be considered as a single group for qualitative descriptions. The tunica intima in these animals was quite thin and composed of an endothelial surface and one or two layers of smooth muscle cells that were separated by ground substance and thin collagen fibers. The tunica media closely resembled that present in human beings and was composed of alternating layers of elastic laminae separated by smooth muscle cells, small collagen and elastic fibers, and ground substance. Control animals at 30 mo were more variable in histologic appearance. Two of the aortas from these animals were similar in appearance to those in the other two control groups. However, three of the animals did have a diffuse intimal thickening that was comprised primarily of fibrous and nonfibrous connective tissues. Maximal intimal thickness in these arteries was $\sim 10 \%$ of the underlying medial thickness. Subendothelial macrophages containing lipidlike material (foam cells) were observed infrequently, and not in all animals nor in all sections from the same aorta.

6-Mo progression. The most consistent and typical changes noted within the tunica intima from this group were the accumulation of vaculated foam cells (presumably lipid-laden macrophages). These lesions were focal or multifocal in distribution, and did not disrupt the underlying innermost elastic lamina nor involve the structures of the tunica media (Fig. 3 $A$ ). One animal in this group had no evidence of macrophages within the intima. In one other animal, an atherosclerotic lesion was noted that was as thick as the underlying tunica media. This lesion was composed of a thin fibromuscular cap with an area of underlying atheronecrosis. Focal mineralization (calcification) was found at the base of the plaque and was associated with disruption of the normal architecture of the media. No morphologic evidence of cholesterol clefts was seen.

12-Mo progression. All animals from this group had diffuse accumulations of vaculated macrophages within the intima (Fig. $3 \mathrm{~B}$ ). In general, the intimas were thin but contained more connective tissue, principally collagen, than was noted in the 6-mo group. Necrosis of occasional individual foam cells could be seen in most of these lesions, and these cells were characterized by pynotic or karyorrhectic nuclei. Three of eight animals had at least one atherosclerotic plaque that was as thick as $50 \%$ of the underlying tunica media. These lesions were characterized by the presence of a fibromuscular cap and necrosis at the base of the lesion. Mineralization was found in one of these lesions, and there were a few scattered but small sterol clefts. The edges of these lesions compared closely to those changes present in the 6-mo progression group, i.e., accumulation of vaculated macrophages.
18-Mo progression. All but one animal in this group had atherosclerotic plaques in the thoracic aorta. In seven of eight animals the plaques were as thick as the underlying tunica media. These lesions were characterized by atheronecrotic cores underlying a well-developed fibromuscular cap (Fig. $3 C$ ). Sterol clefts were noted in six animals with plaques. Mineralization was present in lesions from three animals. Arteries from this group were considerably different qualitatively from either the 6- or 12-month progression group. In the latter two groups the lesions in general were characterized as being fatty streaks, while in the 18-mo group they were obviously plaques, which in several respects were similar to those observed in human beings. The principal change when comparing this group to previous ones was a large increase in fibrous connective tissue and necrosis within the lesions.

24-Mo progression. The thoracic aortas of all animals in this group contained atherosclerotic lesions, which resulted in increases in total wall thickness by a minimum of twofold. In some cases plaques were at least three times the thickness of the media. Of the seven animals in this group, five had lesions with atheronecrosis, five had sterol clefts, and three had mineralization (Fig. $3 \mathrm{D}$ ). The lesions were characterized by increased amounts of collagen and ground substance when compared with the 18-mo progression group. Vacuolated macrophages were present, but were not a prominent feature in the thicker regions of the plaque. Rather, they were most prevalent at the relatively thin areas on the edges of the plaque.

30-Mo progression. All animals in this group had atherosclerotic plaques in the thoracic aorta. Of the five animals, four had mineralization, sterol clefts and atheronecrosis. Typically, the lesions in this group had relatively well-defined areas of atheronecrosis that contained few viable-appearing foam cells. Rather, these macrophages appeared to be in various stages of dying or appeared as "ghost" images. Necrosis and mineralization were present at the base of most lesions (Fig. $3 E$ ). Fibromuscular caps were relatively well developed and contained few vacuolated macrophages. Sterol clefts were increased in number and size when compared with previous progression groups.

QUANTITATIVE ASSESSMENT OF ATHEROSCLEROSIS PROGRESSION. The quantitative data on intimal area, maximum intimal thickness, medial area, and intimal area/medial area ratio for control, progression, and regression groups are presented in Table III. Control animals at 18 and 24 mo had rather thin and discontinuous intimas. There was an increase in intimal area in the 30-mo control group when compared with the two other groups of controls, however these changes were more consistent with a diffuse intimal thickening comprised of collagen with relatively few cells. The cross-sectional intimal area in the progression groups increased slightly from 6 through 12 mo of progression, but there was a marked increase between 12 and $18 \mathrm{mo}$ and perhaps a further increase at $30 \mathrm{mo}$ (Fig. 4). Maximal intimal thickness showed almost a linear increase from 0.14 to $0.77 \mathrm{~mm}$ over the course of 30 mo of progression. Medial area did not seem to change appreciably during the 

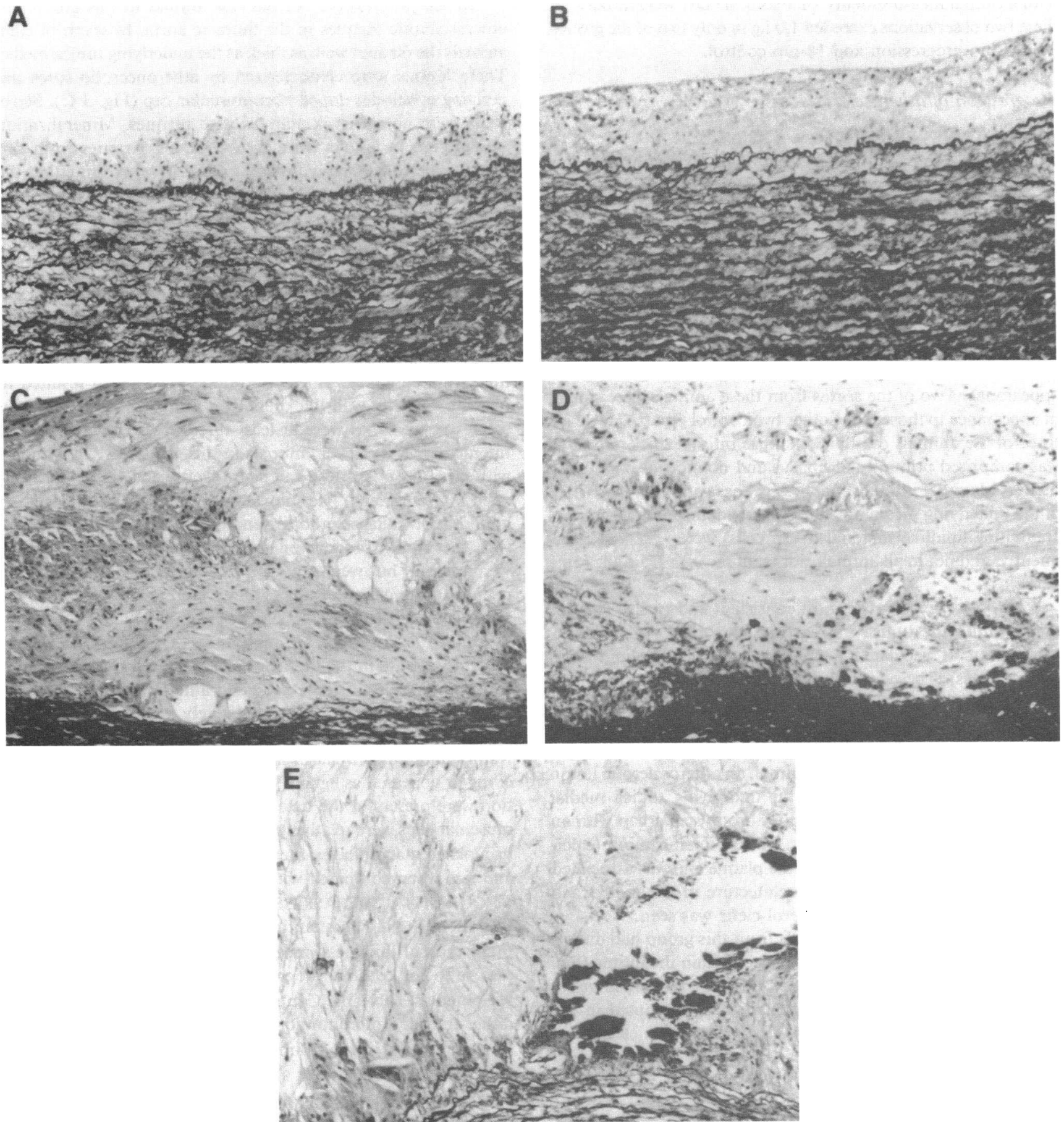

Figure 3. (A) Typical lesion from the 6-mo progression group. Most of the cells within the tunica intima are foam cells. All photomicrographs are from the thoracic aorta. Verhoeff van Gieson stain (original magnification, 100X). (B) Typical lesion from the 12-mo progression group. Most cells are foam cells, but when compared with the 6mo progression group, there is more interstitium, collagen, and ground substance. $(C)$ Typical lesion from an 18-mo progression animal. The plaque is much larger than the 6 - or 12 -mo progression group. There is a fibromuscular cap, atheronecrosis, and occasional sterol clefts in addition to a region that contains collagen. (D) Typical lesion from a 24-mo progression animal. Mineral deposits and necrosis are present at the base of the plaque, and there is an increase in connective tissues when compared with the preceding progression groups. A few cholesterol clefts are present. $(E)$ Typical plaque from an animal progressed for $\mathbf{3 0}$ mo. These lesions were characterized by increased amounts of mineral, atheronecrosis, and sterol cleft accumulation. Most foam cells at or near the edges of plaques appear to be necrotic. 
Table III. Diet-induced Progression and Regression of Thoracic Aorta Atherosclerosis (M. Fascicularis)

\begin{tabular}{llllll}
\hline Group & $n$ & $\begin{array}{l}\text { Intimal } \\
\text { area }\end{array}$ & $\begin{array}{l}\text { Maximum } \\
\text { intimal } \\
\text { thickness }\end{array}$ & $\begin{array}{l}\text { Medial } \\
\text { area }\end{array}$ & $\begin{array}{l}\text { Intimal/ } \\
\text { media }\end{array}$ \\
\hline & & $m m^{2}$ & $m m$ & $m^{2}$ & \\
Progression & & & & & \\
6-mo & 8 & $0.56 \pm 0.5$ & $0.14 \pm 0.2$ & $4.3 \pm 1.6$ & $0.1 \pm 0.1$ \\
12-mo & 8 & $0.71 \pm 0.7$ & $0.24 \pm 0.2$ & $2.8 \pm 0.4$ & $0.2 \pm 0.2$ \\
18-mo & 8 & $3.92 \pm 2.8$ & $0.52 \pm 0.3$ & $3.3 \pm 1.0$ & $1.2 \pm 0.8$ \\
24-mo & 7 & $3.78 \pm 2.4$ & $0.64 \pm 0.2$ & $4.9 \pm 0.8$ & $0.8 \pm 0.6$ \\
30-mo & 5 & $5.42 \pm 1.7$ & $0.77 \pm 0.1$ & $5.3 \pm 1.6$ & $1.1 \pm 0.6$ \\
Regression & & & & & \\
6-mo & 9 & $4.44 \pm 2.5$ & $0.65 \pm 0.3$ & $4.5 \pm 2.5$ & $1.0 \pm 0.6$ \\
12-mo & 9 & $3.50 \pm 1.7$ & $0.56 \pm 0.2$ & $5.3 \pm 1.1$ & $0.7 \pm 0.4$ \\
Control & & & & & \\
18-mo & 5 & $0.01 \pm 0.02$ & $0.01 \pm 0.01$ & $3.8 \pm 0.3$ & $0 \pm 0$ \\
24-mo & 5 & $0.09 \pm 0.14$ & $0.03 \pm 0.03$ & $6.1 \pm 1.8$ & $0.01 \pm 0.02$ \\
30-mo & 5 & $0.35 \pm 0.41$ & $0.07 \pm 0.07$ & $6.5 \pm 1.7$ & $0.04 \pm 0.05$ \\
& & & & & \\
\hline
\end{tabular}

All data expressed as mean \pm standard deviation.

progression phase, however, the mean cross-sectional medial area in the 24- and 30-mo control groups were larger than any group in the progression phase. As expected, the intimal area/ medial area ratio in control groups was quite small (0.01-0.04). There was a tendency for this ratio to increase during the first 18 mo of atherosclerosis progression, and thereafter to remain at $\sim 1$.

CHEMICAL STUDIES. Importance of intimal dissection. Lesions from three animals were dissected and the intima and media of the same lesion were analyzed. A plot of the composition shows (Fig. 5) that intima is richer in cholesterol ester and poorer in phospholipid than the media in each case. The

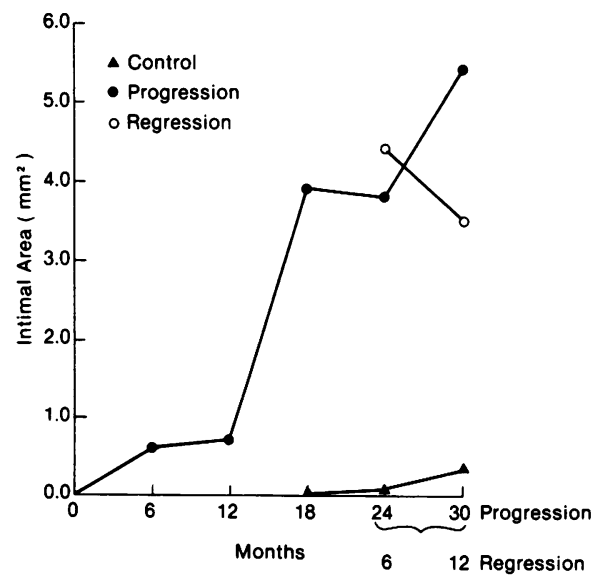

Figure 4. Progression and regression of thoracic aorta atherosclerosis in cynomolgus monkeys: intimal area vs. time.

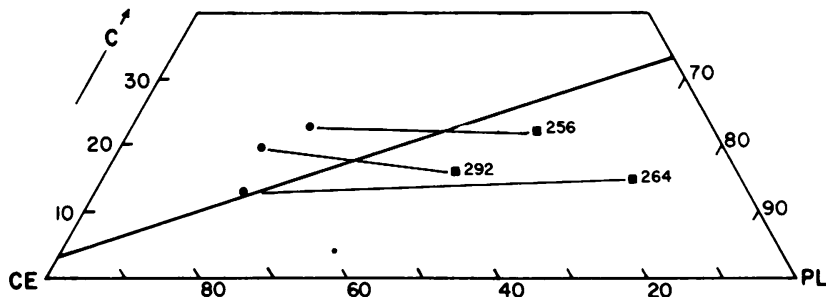

Figure 5. The relative lipid composition of intima and media from the same lesion plotted on triangular coordinates. The figure shows only the bottom of the triangle shown in Fig. 1. CE, cholesterol esters; PL, phospholipids; C, cholesterol. Aortic intimal compositions $(\bullet)$ and media compositions ( $\bullet$ ) from the same lesion are connected by lines. Numbers refer to specific animals. Animals 256 and 292 were 30-mo progression animals, whereas animal 264 was a $24-m o$ progression animal. Intimal compositions are richer in free cholesterol and cholesterol ester than the media compositions. All intima compositions lie above the line and predict that free cholesterol monohydrate crystals should be found, whereas the media compositions are richer in phospholipid and predict only two phases to be present. Compositions of an intima-media preparation would lie on a line connecting the two points and may or may not predict cholesterol monohydrate crystals.

composition of the intima predicts the presence of cholesterol monohydrate crystals in all three lesions (i.e., it falls above the boundary separating two from three phases in Fig. 1), and these crystals were observed in large numbers. The media is rich in phospholipid and does not predict the presence of cholesterol crystals and no crystals were observed in the media. The composition of the whole thickness would fall on a line connecting the intimal and media compositions and thus might or might not predict crystals. Therefore, careful separation of the media from the intima is important for predictive purposes.

Relative lipid composition of arterial intimas. The relative percentage of cholesterol esters, phospholipids, and free cholesterol are plotted on triangular coordinates for both the ilial lesions and the aortic lesions in Fig. 6. The trends are similar to those of human lesions, but the iliac contains slightly less free cholesterol than the aorta and there was no difference in cholesterol compositions at 24 and $30 \mathrm{mo}$. The composition of intima of the control animals is very low in cholesterol ester and rich in phospholipid, similar to young normal adults (see Fig. 1). After 24 mo of cholesterol feeding, the composition has moved towards the cholesterol ester apex, remaining in the twophase region. The composition is rather similar to fatty streak, though containing slightly less cholesterol ester than the human fatty streak (3). This may be due to some difficulty in removing all of the media from these lesions, as media would dilute the cholesterol ester concentration (see Fig. 5, above). In the aorta at $30 \mathrm{mo}$, the composition has moved over the line into the three-phase region. These findings corroborate the increased severity noted in the histological sections in the aorta. From the composition of the aorta at 30 mo we predict the presence of cholesterol crystals. 

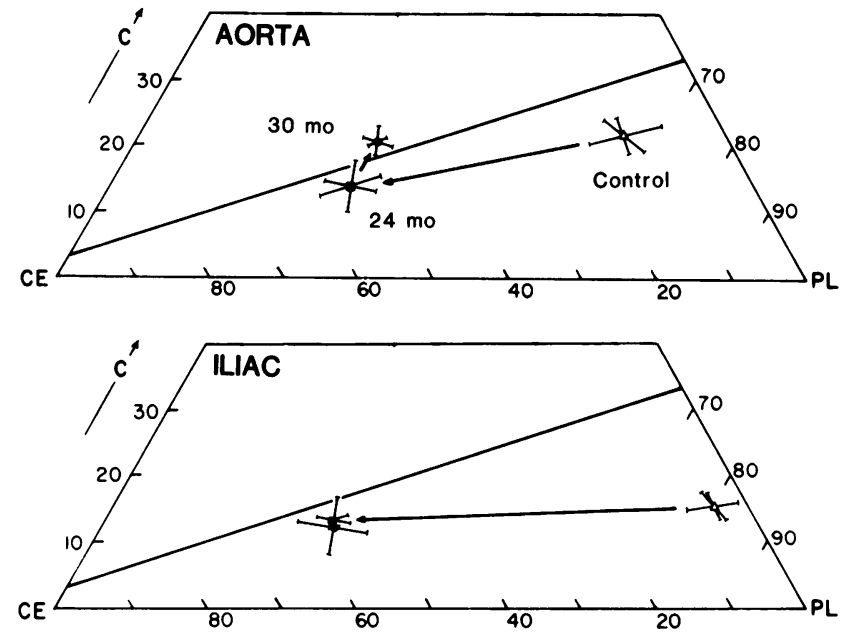

Figure 6. Relative lipid composition of the arterial wall in progression. Points represent the mean compositions of all of the lesions within a group and the lines through the point represent \pm 1 SEM of each of the determinations. $\Delta$, control artery; $₫, 24-\mathrm{mo}$; and $\bullet, 30$-mo progression. The mean compositions of intimas of both the aorta and iliac arteries are shown. There is no change between 24 and 30 mo in the iliac arteries, but in the aorta the lesions become richer in free cholesterol and at $\mathbf{3 0}$ mo they pass above the line into the threephase region where crystals of cholesterol monohydrate would be expected to be present. Abbreviations are as in Fig. 5.

PHYSICOCHEMICAL STUDIES. Cholesterol monohydrate crystals. The semiquantitative estimate of the number of crystals in the lesion is plotted against the percentage of lesions examined having 0 to $>20$ crystals per 10 low-power fields in Fig. 7. In the controls, no cholesterol crystals were seen in any of the intimas. At 6 and 12 mo no crystals were seen in most of the lesions, but an occasional lesion had a few small cholesterol crystals. At 24 mo, about half the lesions have cholesterol crystals, and a few lesions are beginning to show rather large numbers (>20 per 10 low-power fields). At $30 \mathrm{mo}$, the majority of lesions show large numbers of large crystals. Thus, the number of cholesterol monohydrate crystals increased with progression and appeared to accelerate between 24 and $30 \mathrm{mo}$. This corroborates the chemical finding that predicts cholesterol crystals in the aortic lesions at 30 mo (Fig. 6).

Lipid-laden foam cells and extracellular lipid droplets. The estimated number of lipid-laden foam cells in lesions appears to undergo changes during progression. Fig. 8 shows a semiquantitative estimate of foam cell number at 6, 12, 24 and 30 mo. At 6 mo all of the lesions have many foam cells. As atherosclerosis progresses from 12 to 24 and from 24 to $30 \mathrm{mo}$, the number of lesions with many foam cells decreases. By 30 mo of progression, the majority of the lesions have few or no identifiable foam cells. Whether this represents a displacement of foam cells by other material within the lesion or a true decrease in the foam cell number is not known. Extracellular droplets are numerous in all progression groups.

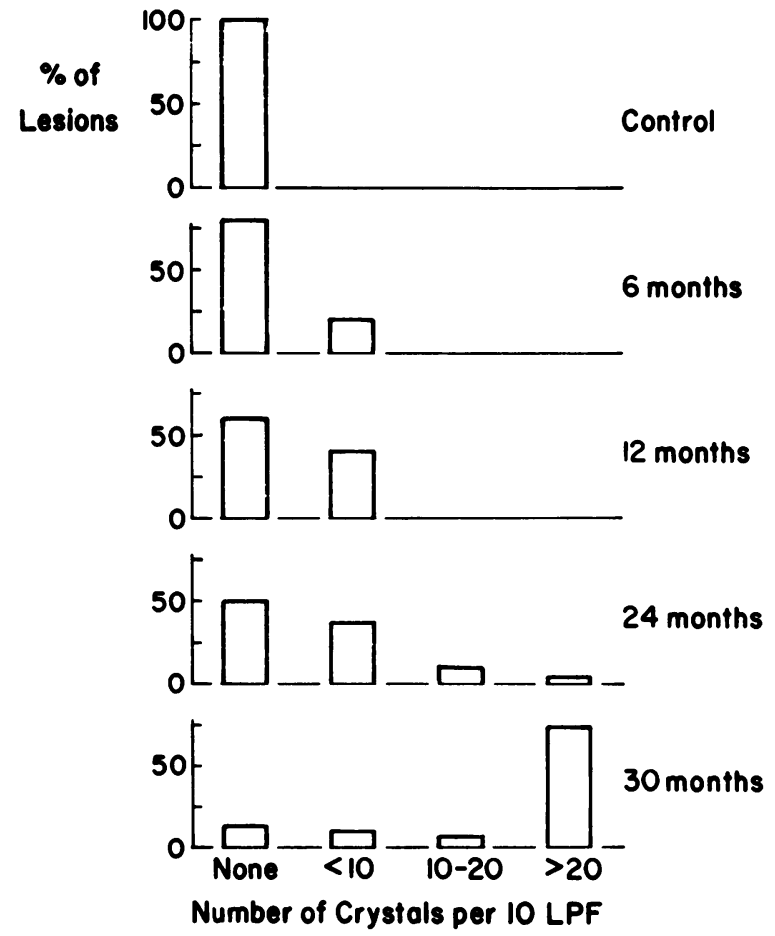

Figure 7. Distribution and estimated number of cholesterol monohydrate crystals during progression. A semiquantitative assay of the number of crystals is represented as $0,<10,10-20$, or $>20$ crystals per 10 low-power fields observed in en face preparations of the intima are plotted against the percentage of lesions in each category. Very few lesions at 6 mo have crystals and they were small, whereas many large crystals were seen in lesions at $30 \mathrm{mo}$.

In control animals, neither cholesterol ester-containing foam cells nor cholesterol ester droplets were found in the intima. This is remarkable, in that a droplet $1 \mu \mathrm{m}$ in diameter contains $\sim 0.5 \mathrm{pg}$ of cholesterol ester, and the inability to see any droplets

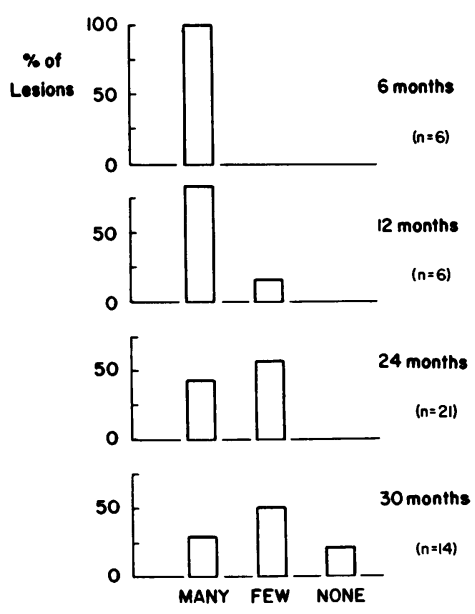

Figure 8. The estimated number of foam cells in the intimas during progression. At $6 \mathrm{mo}$ all of the lesions have many foam cells, while during progression the number of foam cells decreases so that at $\mathbf{3 0}$ mo most of the lesions have few or no foam cells. 
in hundreds of low-power fields in normal intima enhances the idea that arteries from animals fed a diet devoid of cholesterol (monkey chow) are extremely resistant to the formation of extraor intracellular cholesterol ester droplets. The relatively small amount of cholesterol ester noted in the composition (Fig. 6) is therefore probably submicroscopic, and may be bound, intact, or denatured lipoprotein.

Cholesterol ester melting. A comparison of the extracellular droplet melting and intracellular cholesterol ester melting at 6 , 24, and $30 \mathrm{mo}$ is given in Fig. 9. The cumulative melting curves for intra- and extracellular droplets are rather similar after 6 mo of progression, but begin to diverge at later periods, so that after 30 mo the foam cell cholesterol esters melt at a distinctly

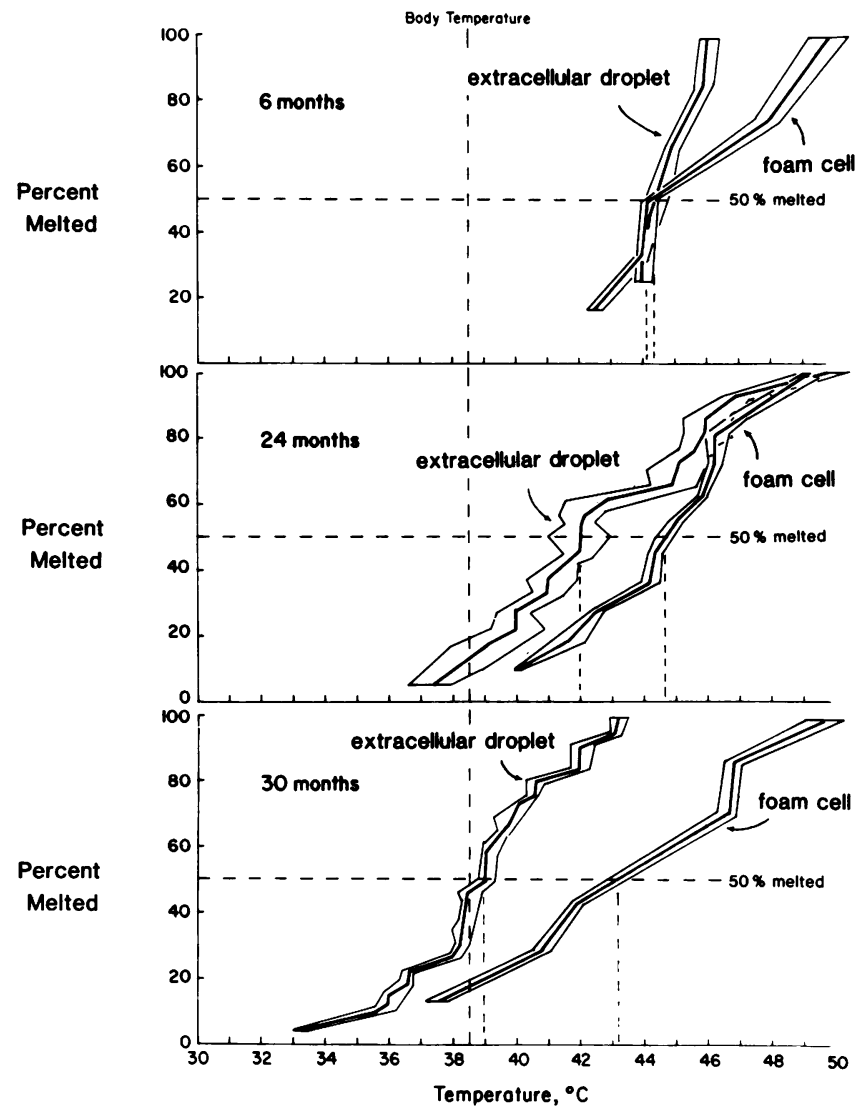

Figure 9. Foam cell cholesterol ester vs. extracellular droplet melting during progression. Cellular cholesterol ester and extracellular droplet melting profiles plotted as the percentage of lesions which have undergone melting as a function of temperature. The dark line represents the mean of the lesion melting and the fine lines represent \pm 1 standard deviation of the mean for that lesion. Note that at 6 mo both droplets and foam cells have high melting temperatures well above body temperature; at $\mathbf{2 4}$ mo, droplets and cells are still high but droplets have decreased somewhat and by 30 mo the droplet melting is several degrees below the foam cell melting profile, indicating different chemical compositions of at least some of the extracellular droplets from intracellular cholesterol ester. higher temperature than the extracellular esters. The temperature at which $50 \%$ of all the cholesterol ester melted was lower for the extracellular droplets $\left(39^{\circ} \mathrm{C}\right)$ compared with the cells $\left(43^{\circ} \mathrm{C}\right)$ at $30 \mathrm{mo}$. In fact at $43^{\circ} \mathrm{C}$ - the midpoint for cells-virtually all the extracellular droplets had melted. This suggests that even though droplets from cells ruptured during preparation may contaminate the extracellular droplet fraction, the composition is richer in the lower-melting esters and different from the composition within cells. This suggests a different origin for some of these droplets.

\section{Regression of atherosclerosis}

QUALITATIVE EVALUATION. 6-Mo regression. The atherosclerotic lesions in the thoracic aorta of animals from the 6-mo regression group were characterized by increases in connective tissue components, particularly collagen, when compared with either the 18 - or 24-mo progression groups. There were relatively fewer foam cells throughout the intima, and these cells, when present, usually were found in small clumps between layers of collagen. Mineral was present in five of the nine animals and was surrounded by both fibrous and nonfibrous connective tissues. Qualitatively, fewer and smaller necrotic regions were observed in this group when compared with the 18- and 24-mo progression groups. Five of the nine animals had large sterol clefts that were predominantly located at the base of the plaque (Fig. $10 \mathrm{~A}$ ).

12-Mo regression. The lesions in animals that had been fed an atherogenic diet for 18 mo followed by a monkey chow diet for 12 mo were qualitatively different from the 18- and 24-mo progression group and from the animals regressed for $6 \mathrm{mo}$. In general, the intimas were compact-appearing and were composed of dense accumulations of collagen. There were relatively few foam cells present in these lesions. Mineralization was found in four animals of nine in this group and sterol clefts in only three. Necrotic foci were present but were reduced in both size and number when compared with either the 6-mo regression group or with the 18- or 24-mo regression groups (Fig. $1 \mathrm{~B}$ ).

QUANTITATIVE EVALUATION. Effect of reduction in serum cholesterol concentrations on several morphological characteristics of atherosclerosis is presented in Table III. Aortas from animals that had been fed a high-cholesterol-containing diet for $18 \mathrm{mo}$, and then a noncholesterol-containing diet for $6 \mathrm{mo}$, had larger mean intimal areas $\left(4.44 \mathrm{~mm}^{2}\right)$ and maximum intimal thicknesses than did the $18-\mathrm{mo}\left(3.92 \mathrm{~mm}^{2}\right)$ or $24-\mathrm{mo}$ $\left(3.79 \mathrm{~mm}^{2}\right)$ progression group. Intimal area/medial area ratios were lower in the 6-mo regression group; however this appears to be a result of the larger medial area in the regression group $\left(4.5 \mathrm{~mm}^{2}\right)$, when compared with the 18 -mo progression group $\left(3.3 \mathrm{~mm}^{2}\right)$. These findings suggest that the lesions certainly did not decrease in size and may have even increased during 6-mo regression.

Animals that progressed for $18 \mathrm{mo}$ and then regressed for $12 \mathrm{mo}$ had smaller mean intimal areas $\left(3.5 \pm 1.7 \mathrm{~mm}^{2}\right)$ than did either the $18-\mathrm{mo}$ progression group $\left(3.92 \pm 2.8 \mathrm{~mm}^{2}\right)$ or the 6-month regression group $\left(4.44 \pm 2.5 \mathrm{~mm}^{2}\right)$. 


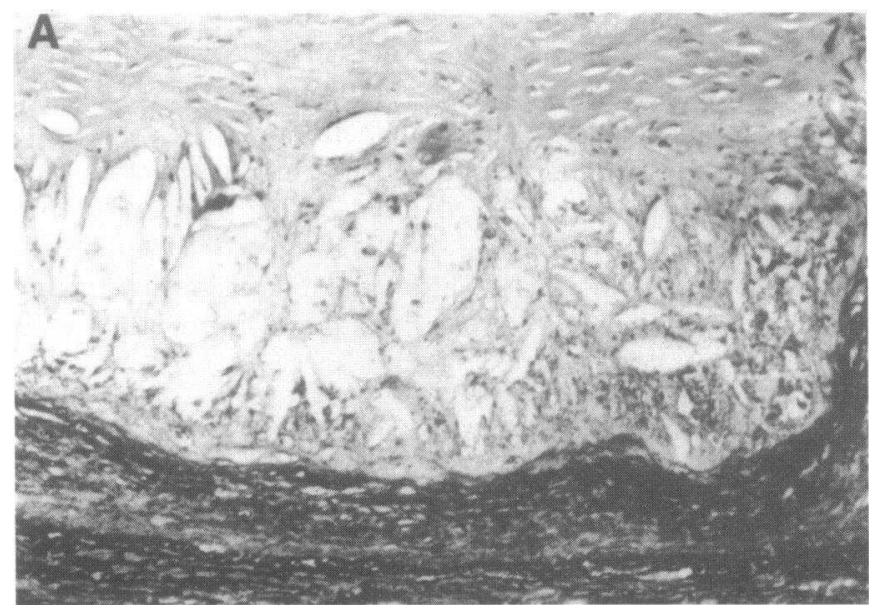

Figure 10. (A) A photomicrograph of one of the more complicated lesions present in the group of animals progressed for $18 \mathrm{mo}$ and then regressed for $6 \mathrm{mo}$. There is an accumulation of large sterol clefts and mineral granules at the base of this plaque. Some necrosis is also seen. The remainder of this plaque showed an accumulation of dense fibrous connective tissues. Thoracic aorta. Verhoeff van Gieson stain. $\times 100$. $(B)$ Typical lesion from an animal that was pro-

In general, when comparisons are made between regression and progression groups (Fig. 4), there is a tendency for intimal areas to increase or stabilize at $6 \mathrm{mo}$ and for lesions to decrease in size over the 12-mo regression period.

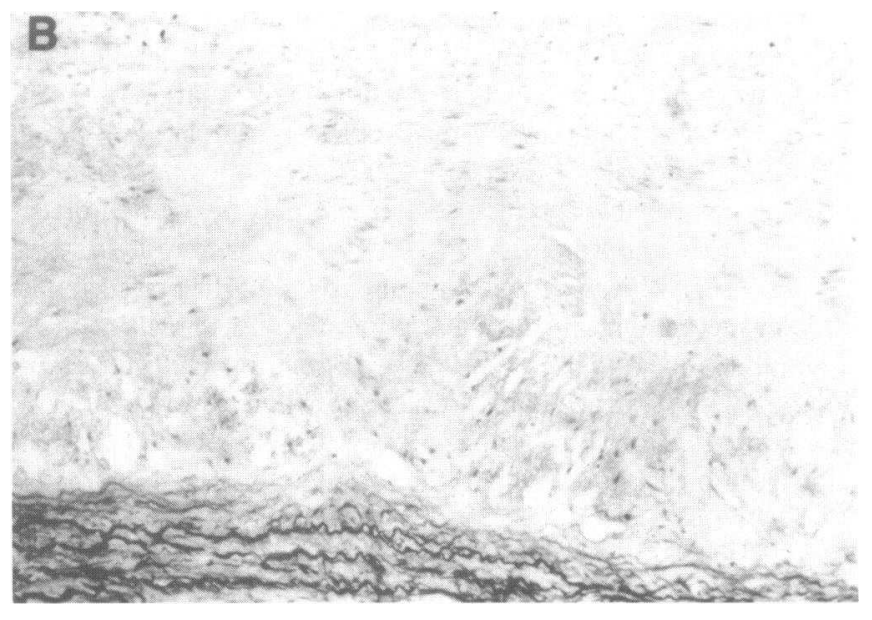

gressed for $18 \mathrm{mo}$ and then regressed for $12 \mathrm{mo}$. The plaque appears quite compact and is composed predominantly of collagen, smooth muscle cells, and fibroblast-like cells. Small amounts of mineral and atheronecrosis are found at the base of the plaque. A small accumulation of sterol clefts can also be seen in this photomicrograph. Thoracic aorta. Verhoeff van Gieson stain. $\times 100$.

Chemical studies. The chemical composition of lesions in the 24-mo progression and 6- and 12-mo regression animals are shown in Fig. 11. A very curious phenomenon was noted. The 6-mo regression animals were clearly different from either
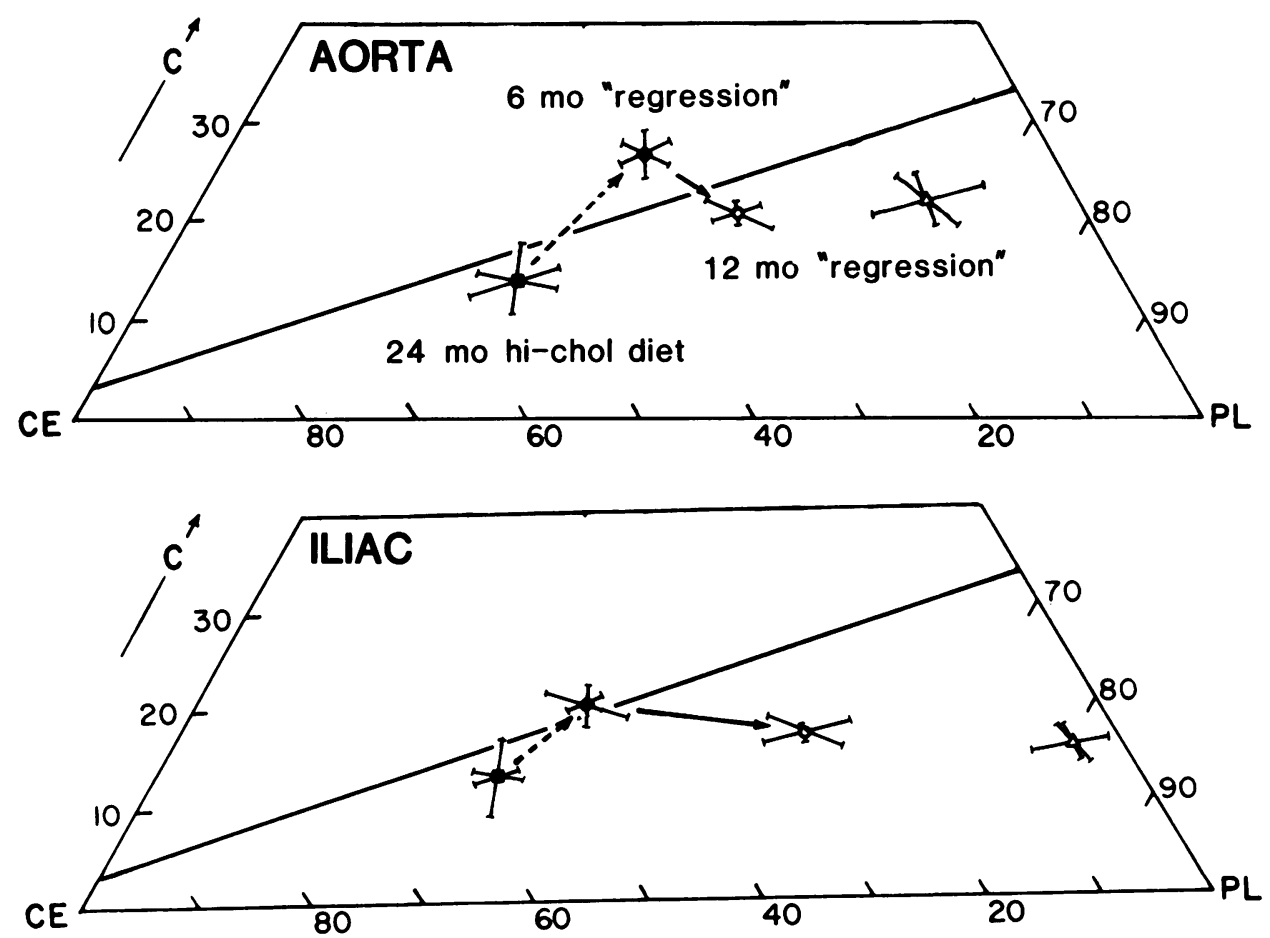

Figure 11. The chemical changes during regression plotted on triangular coordinates. Chemical composition mean \pm 1 standard error of the mean are plotted for control intima $(\Delta)$ at 24-mo progression ( $\square$ ), 6-mo regression (๑) and 12-mo regression (o). Both the aorta and iliac artery mean composition at 6-mo regression is above the line and crystals of cholesterol monohydrate would be expected. The 12-mo regression has returned (solid arrow) below the line in a direction towards the control artery. Although crystals would not be expected from the chemical composition, they are found by polarizing microscopy in at least two-thirds of these lesions (see Fig. $12 \mathrm{~A}$ ). Abbreviations are as in Fig. 5 . 
A

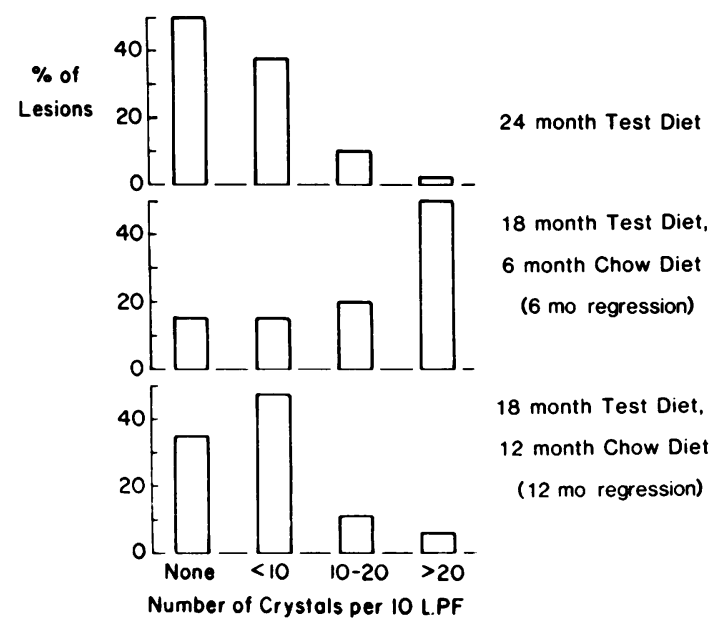

B
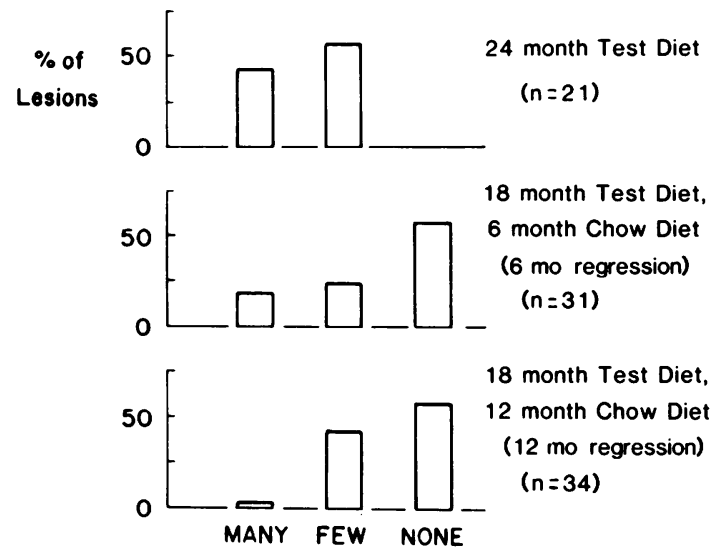

Figure 12. Distribution of cholesterol monohydrate crystals and the estimated number of foam cells during regression. $(A)$ Estimated number of cholesterol monohydrate crystals. The percent of lesions containing $0,<10,10-20$, or $>20$ crystals per 10 low-power fields is plotted. In the 24-mo progression group, $50 \%$ of the lesions had no crystals and only a few crystals were present in most of the other lesions. At 6-mo regression most of the lesions had large numbers of crystals, however, by 12-mo regression large numbers of crystals disappeared and even though two-thirds of the lesions still had crystals, they were usually few in number and present at the base of the lesion. $(B)$ Estimated number of foam cells is given as the percent of lesions having many, few, or none. In the 24-mo progression group all the animals have foam cells, and they were roughly equally distributed between many and few. The number of foam cells gradually decrease during the regression period so that $>50 \%$ of the lesions had no observable foam cells at 12 -mo regression. the control animals or the 24-mo progression animals. In fact, both in the aorta and in the iliac arteries, the 6-mo regression animals had increased free cholesterol and decreased cholesterol ester and moved above the line into the three-phase region. The composition of the 6-mo regressed lesions is significantly different (as shown by the error bars) from the 24-mo progressed lesions, predicting that cholesterol crystals should be present in the 6mo regression lesions. However, the 12-mo regression animals have lost both cholesterol ester and free cholesterol and have moved back down below the phase boundary into the two-phase regions, towards the lipid composition of the control animals. The plots predict that cholesterol monohydrate crystals should have disappeared after 12-mo regression.

Cholesterol monohydrate crystals. The chemical composition (Fig. 11) predicts that cholesterol crystals would have increased in the 6-mo regression animals, and disappeared or at least decreased in the 12 -mo regression animals. A semiquantitative estimate of the number of crystals per lesion is given in Fig. 12 $A$. About half of the animals after 24 mo of progression have no crystals, as determined by physical microscopy, and only a very few had large numbers of crystals ( $>20$ per 10 low-power fields). However, the 6-mo regression animals are striking in that at least $50 \%$ of their lesions contain $>20$ crystals per 10 low-power fields. Furthermore, after 12-mo regression, these large numbers of crystals have decreased, so that some lesions have no crystals and most of the animals have only a few $(<10$ per 10 low-power fields). Interestingly, the crystals in these lesions appear to lie at the base of the lesion next to the internal elastic lamina, and often next to mineral deposits. The great profusion of crystals throughout many parts of the lesion noted in the 6-mo regression animals was no longer present after 12 mo.

Lipid-laden foam cells and extracellular droplets. The estimated number of foam cells also changed during regression. At 24-mo progression, all the lesions have some and often many foam cells (Fig. $12 \mathrm{~B}$ ). However, after 6 and 12 mo of regression, foam cells are difficult to find and many of the lesions have no identifiable foam cells. Extracellular droplets decrease at 6 mo of regression and at 12 mo are difficult to find ( $<5$ per 10 lowpower fields).

Cholesterol ester melting in intra- and extracellular droplets. The mean melting temperature of cholesterol esters in foam cells and extracellular droplets is shown in Fig. 13. The curve for the 24-mo progression group shows that the mean lesion transition varies between 40 and $49^{\circ} \mathrm{C}$, with a midpoint of $\sim 45^{\circ} \mathrm{C}$. Actually, no lesions have mean melting points below body temperature. In the animals at 6-mo regression, inadequate foam cells were found to do reliable melting studies, and at 12 mo, out of 15 identifiable lesions with foam cells, only 2 were found to have cholesterol ester melting behavior, and this melting occurred considerably below body temperature. 13 of 15 lesions with foam cells had no cholesterol ester transitions in cells at temperatures down to $26^{\circ} \mathrm{C}$, indicating that lipid composition of the cells had been markedly altered during the regression period. A similar trend was noted in the extracellular droplets 


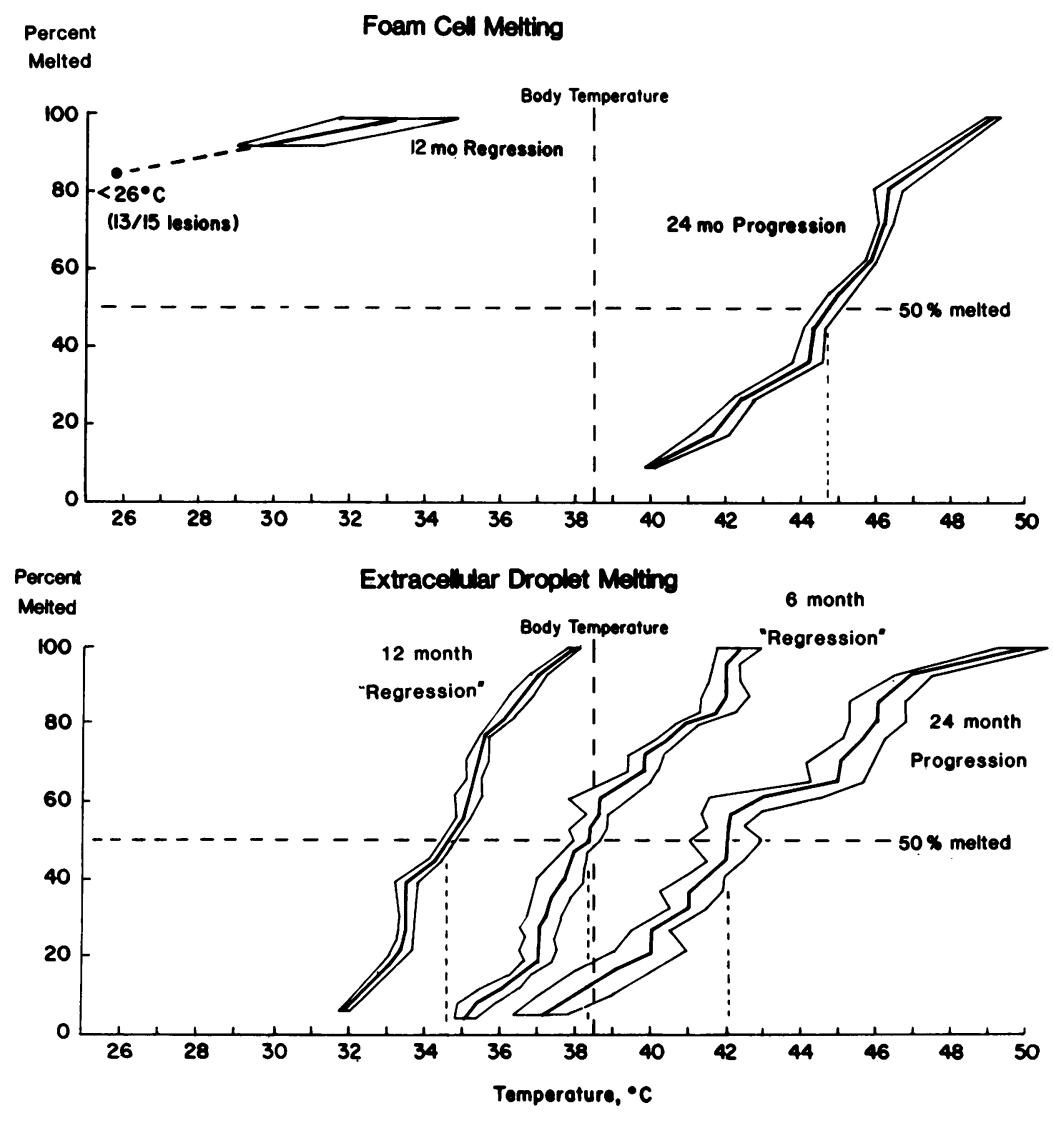

Figure 13. The cholesterol ester melting of foam cells and extracellular droplets during regression, plotted as the percentage of cells that have melted at a given temperature. For comparison, the 24-mo progression group shows that both cells (median melting at $45^{\circ} \mathrm{C}$ ) and droplets (median melting at $42^{\circ} \mathrm{C}$ ) have high melting temperatures. During regression, cells become difficult to find and at 30 mo have extremely low melting points, many below $26^{\circ} \mathrm{C}$. Extracellular droplets also show a decrease in the melting profile such that at 12 -mo regression the entire population of droplets melts below body temperature. (bottom of Fig. 13); while there was a profusion of extracellular droplets in the 24-mo progression animals, droplets became more and more difficult to find as the regression period lengthened, so that the number of extracellular droplets occurring at 12 mo regression was $<5$ per 10 low-power fields. The cumulative melting curves of extracellular droplets were shifted down in the 6- and 12-mo regression groups, the mean melting decreasing from $42^{\circ} \mathrm{C}$ in the $24-m o$ progression group to $38.3^{\circ} \mathrm{C}$ at 6 mo of regression and to $34.6^{\circ} \mathrm{C}$ after $12 \mathrm{mo}$ of regression. This indicates a marked change in the composition of the droplet, presumably toward lower melting esters.

\section{Discussion}

The purpose of this study was twofold: first, to determine the pathological and physical-chemical changes that occur during the progression of atherosclerosis produced by high cholesterol diet, and second, to understand the changes in the arterial wall that occur during regression. Physical-chemical studies of human lesions $(3,7)$ imply that human lesions progress from small fatty streaks through intermediate lesions to plaques (Fig. 1). However, until noninvasive lesion quantitation can be precisely developed (21) it is impossible to follow the histological and physical-chemical development of lesions in human arteries. For that reason we have turned to the nonhuman primate and designed an experiment in which animals were induced to form atherosclerosis by high-cholesterol diet and then killed periodically for up to $30 \mathrm{mo}$. The method of induction with a highcholesterol diet produces a sharp rise in serum cholesterol, which is mainly carried in a large, high melting atherogenic LDL (20). After 18 mo of a high-cholesterol diet, regression was induced by returning the animal to a normal chow diet. On chow, the serum cholesterol fell $<300 \mathrm{mg} / \mathrm{dl}$ in $2 \mathrm{mo},<200$ in $4 \mathrm{mo}$, and was essentially at control values by the end of the regression period. Lesions from progression and regression groups from iliac arteries and aorta were examined by histological, morphometric and physical-chemical techniques. The findings in the iliac arteries were similar to those in the aorta, although perhaps less severe.

During the first 12 mo of progression the intima increased moderately in area and thickness (Table III) with a foam-cell lesion (Fig. 8) of a fatty streaklike appearance (Figs. $3 A$ and $B)$. The composition was very rich in high-melting cholesterol esters. Both cellular and extracellular cholesterol ester have similar melting profiles (Fig. 9), which suggests that the extracellular droplets originated from ruptured cells. Only rare necrosis and cholesterol crystals (Fig. 7) and little collagen were present. By 18 to 24 mo the intimal area and thickness increased sharply (Table III), and early necrosis (Figs. $3 C$ and $D$ ) and cholesterol 
crystals were present in $50 \%$ of the lesions (Fig. 7). Foam cells were reduced (Fig. 8) and located mainly at the margin of lesions. The melting of extracellular cholesterol esters was then lower than those in foam cells although both were still largely above body temperature (Fig. 9).

By $30 \mathrm{mo}$, more marked necrosis was present (Fig. $3 E$ ) and large numbers of cholesterol crystals predominated (Fig. 7). Interestingly, while the estimated number of foam cells was further decreased (Fig. 8), small clumps, some degenerating, were still present particularly at the margin of the lesions; and they continued to have high-melting cholesterol ester droplets (Fig. 9), similar to those seen in earlier lesions. It is quite possible that these cells remove the large, high-melting atherogenic LDL (20) from the circulation, process the lipoprotein, store the cholesterol esters, and then degenerate. The chemical composition at 30 mo in the aorta becomes relatively richer in free cholesterol than at 24 mo (Fig. 6); and this could be due to the hydrolysis of some cholesterol ester by hydrolytic enzymes (perhaps lysosomal) and the formation of free cholesterol from cholesterol ester. The process would presumably occur towards the interior of the plaque and therefore free cholesterol might not be readily removed by "reverse cholesterol transport" mechanisms such as high density lipoprotein and would precipitate upon reaching a critical concentration above solubility (22). It is of interest to note that in the microdissection of human plaques carried out by Smith and Slater (23), foam cells were found at the margins of fatty plaques as we have confirmed in this study. The plot of the composition of the edge region of the plaque (given in Fig. 4 of reference 7) indicated that the composition was very much like an intermediate lesion (see Fig. 1), whereas the composition of the plaque interior was much richer in free cholesterol, falling high up in the three-phase region (7). There is now evidence that, once crystallization of cholesterol monohydrate occurs, such crystals are in extremely slow exchange with plasmafree cholesterol (24). Such crystals would not be expected to dissolve readily $(7,24)$.

The data can allow us to speculate on the mechanisms of progression. Atherosclerosis is induced in this model by the production of a high molecular weight, high melting LDL (20). Cholesterol uptake by intimal cells is more rapid than removal, and positive cellular cholesterol balance occurs. Lipoprotein cholesterol is processed and stored in cells (25) as a very highmelting cholesterol ester (Fig. 9). Such cells become foam cells with high melting cholesterol esters similar to a fatty streak. However, the fatty streaks in humans have somewhat lower melting cholesterol esters $(3,26)$. With continued high levels of large, high-melting LDL the cells become engorged and some event occurs which begins the degeneration and necrosis of the foam cells in the more internal part of the lesion. This could be due to an inability to mobilize free cholesterol out of the lysosomes with its subsequent crystallization within lysosomes leading to rupture and release of the lysosomal contents into the cell. Or it could be an inability to remove free cholesterol from the cell and crystallization within the cytoplasm of the cell, leading to cell death. Whatever the mechanism, increased free cholesterol content, cholesterol monohydrate crystallization and necrosis appear to go hand in hand. The vessel wall appears to be special in this respect, since the foam cells of the spleen and liver in Tangiers disease (15) and the foam cells in the liver of a patient with cholesterol ester storage disease (27) accumulate very large quantities of cholesterol ester but do not undergo cholesterol crystal formation or necrosis. In general, we conclude that the progression of atherosclerosis in this nonhuman primate model appears to be similar to that postulated for humans $(3,12)$.

The findings during the regression period were somewhat unexpected, particularly at $6 \mathrm{mo}$. A large number of investigators have shown that induced atherosclerotic lesions in nonhuman primates can regress and that lipids decrease in quantity in the regressed lesions (e.g., see references 28-36). However, the physical chemistry of these changes has not been examined. Unexpectedly, in the 6-mo regression group, we found that the composition contained relatively less cholesterol ester and more free cholesterol and fell in a region of the triangular-phase diagram where we would expect cholesterol crystals to precipitate (Fig. 11). Physical microscopy indicated large numbers of large cholesterol monohydrate crystals (Fig. $12 \mathrm{~A}$ ) and the histology corroborated this finding (Fig. $10 \mathrm{~A}$ ). Furthermore, cholesterol ester-laden cells and droplets were rather sparse, confirming that a decrease in the mass of cholesterol ester had occurred as has been found by others (see 29,30). The decrease in the number of foam cells was accompanied by a marked decrease in the melting of the extracellular cholesterol ester droplets (Fig. 10 $A$ ) and probably the cellular cholesterol esters, although cells were so sparse that good data could not be obtained in the 6mo regression group. The data suggest that the regression period may have stimulated cholesterol ester hydrolysis, which initially resulted in a relative decrease in cholesterol esters and a relative increase in free cholesterol, as shown in Fig. 11. Physical-chemical studies strongly suggest that some of this free cholesterol precipitated to form the large cholesterol monohydrate crystals found in these lesions. Some of the decrease in cholesterol ester could be by loss of foam cells either by migrating out of the lesion or by degeneration and hydrolysis of the released cholesterol esters. Histologically, there appeared to be more collagen in these lesions, but neither lesion thickness nor intimal area decreased during the first 6 mo of regression. Perhaps the intimal volume (as reflected by area) taken up by cholesterol esters before regression was replaced by collagen and cholesterol crystals at $6 \mathrm{mo}$.

It has been predicted (7) that because crystalline cholesterol is relatively inert that it would be difficult to mobilize during regression. The extremely slow exchange of labeled plasma cholesterol with cholesterol monohydrate crystals isolated from a human atherosclerotic plaque (24) support the idea of the inertness of the crystal phase. Thus, one would expect that the removal of cholesterol crystals would be slow during regression, but the fact that cholesterol crystals were larger and appeared 
to be increased over the 24-mo progression animal, strongly suggests that crystals actually grew during the 6-mo period of regression. However, by 12 mo the crystals were decreased in size and number and appeared to rest in clumps near the internal elastic lamina and near mineral deposits. The composition of the arteries had returned to the two-phase region and approached normal composition. The 12-mo regression composition does not predict cholesterol crystals, therefore, their presence indicates the slow dissolution of the crystals within the vessel wall. This is not surprising since the crystals appeared to be sequestered deep in the base of the plaque. Almost total absence of cholesterol ester and foam cells in these 12-mo regression lesions is interesting. The fact that the cells examined had extremely low melting cholesterol esters indicates that the composition of the inclusions within these cells is very different from those of foam cells of the progression lesions. It is possible that these foam cells are macrophages in the process of scavenging necrotic lipid and thus contain some triglyceride, which would lower the melting point of cholesterol esters within cells (13). The melting point of the remaining droplets was also considerably lower and rather like that of the melting of the low density lipoproteins of similar animals during regression (20).

In conclusion, the regression caused by lowering of serum cholesterol from $\sim 800 \mathrm{mg} / \mathrm{dl}$ to $<200 \mathrm{mg} / \mathrm{dl}$ appears to first result in worsening of the lesion with cholesterol monohydrate precipitation and only after a longer period of time (1 yr) do these cholesterol crystals decrease and the vessel begin to truly regress toward a more normal composition and morphology.

\section{Acknowledgments}

We wish to thank Ms. Hermina Trillo for special histological stains; Mrs. Marie Pyler, Ms. Nancy Julian, and Ms. Lea Nading for routine histology; Dr. T. Clarkson for helpful discussions; Dr. L. Rudel for serum cholesterol measurements; Dr. Robert Martin for help with microscopy; and Ms. Irene Miller for preparing the manuscript.

This work was supported by Public Health Service grants HL26335, HL07291, HLO7224, and HV-7-2925.

\section{References}

1. Classification of atherosclerotic lesions. Report of a study group. 1958. WHO Tech. Rep. Ser. 143:3-20.

2. Panganamala, R. V., J. C. Geer, H. M. Sharma, and D. G. Cornwell. 1974. The gross and histologic appearance and the lipid composition of normal intima and lesions from human coronary arteries and aorta. Atherosclerosis. 20:93-104.

3. Katz, S. S., G. G. Shipley, and D. M. Small. 1976. Physical chemistry of the lipids of human atherosclerotic lesions. J. Clin. Invest. 58:200-211.

4. Katz, S. S. 1981. The lipids of grossly normal human aortic intima from birth to old age. J. Biol. Chem. 256:12275-12290.

5. Lange, P. D., and W. Insull, Jr. 1970. Lipid droplets in atherosclerotic fatty streaks of human aorta. J. Clin. Invest. 48:1479-1488.

6. Hata, Y., and W. Insull, Jr. 1973. Significance of cholesterol esters as liquid crystals in human atherosclerosis. Jpn. Cir. J. 37:269-275.
7. Small, D. M., and G. G. Shipley. 1974. Physical-chemical basis of lipid deposition in atherosclerosis. Science (Wash. DC). 185:222229.

8. Katz, S. S., and D. M. Small. 1980. Isolation and partial characterization of the lipid phases of human atherosclerotic plaques. $J$. Biol. Chem. 1255:9753-9759.

9. Smith, E. B. 1965. The influence of age and atherosclerosis on the chemistry of aortic intima. Part I. The Lipids. J. Atheroscler. Res. 5:224-240.

10. Hoff, H. F., C. L. Heideman, and J. W. Gaubatz. 1980. Lowdensity lipoproteins in the aorta. In Atherosclerosis. V. A. M. Gotto, Jr., L. C. Smith, and B. Allen, editors. Springer-Verlag, New York. 533536.

11. Hollander, W., J. Paddock, and M. Colombo. 1979. Lipoproteins in human atherosclerotic vessels. Exp. Mol. Pathol. 30:144-171.

12. Small, D. M. 1977. Cellular mechanisms for lipid deposition in atherosclerosis. N. Engl. J. Med. (Semin. Physiol.). 297:873-877 and 924-929.

13. Small, D. M. 1970. The physical state of lipids of biological importance-cholesterol esters, cholesterol and triglyceride. In Surface Chemistry of Biological Systems. E. Blank, editor. Plenum Publishing Co., New York. 55-84.

14. Loomis, C. R., G. G. Shipley, and D. M. Small. 1979. The phase behavior of hydrated cholesterol. J. Lipid Res. 20:525-535.

15. Katz, S. S., D. M. Small, J. G. Brook, and R. S. Lees. 1977. The storage lipids in Tangier disease: a physical-chemical study. J. Clin. Invest. 59:1045-1054.

16. Bond, M. G., M. L. Adams, and B. C. Bulock. 1981. Complicating factors in evaluating coronary artery atherosclerosis. Artery. 9:21-29.

17. Folch, J., M. Lees, and G. H. Sloane Stanley. 1957. A simple method for isolation and purification of total lipids from animal tissues. J. Biol. Chem. 226:497-509.

18. Downing, D. T. 1968. Photodensitometry in the thin-layer chromatographic analysis of neutral lipids. J. Chromatogr. 38:91-99.

19. Admirand, W. H., and D. M. Small. 1968. The physico-chemical basis of cholesterol gallstone formation in man. J. Clin. Invest. 47:10451052.

20. Tall, A. R., D. M. Small, D. Atkinson, and L. L. Rudel. 1978. Studies on the structure of low density lipoproteins isolated from Macaca fascicularis fed an atherogenic diet. J. Clin. Invest. 62:1354-1363.

21. Bond, M. G., W. Insull, Jr., S. Glagov, A. B. Chandler, and J. F. Cornhill, editors. 1982. Clinical Diagnosis of Atherosclerosis. Quantitative Methods of Evaluation. Springer-Verlag, NY.

22. Small, D. M. 1980. Cholesterol nucleation and growth in gallstone formation. N. Engl. J. Med. (Editorial). 302:1305-1307.

23. Smith, E. B., and R. S. Slater. 1972. The microdissection of larger atherosclerotic plaques to give morphologically and topographically defined fractions for analysis. Part I. The lipids in the isolated fractions. Atherosclerosis. 15:37-56.

24. Katz, S. S., D. M. Small, F. R. Smith, R. B. Dell, and D.-W. S. Goodman. 1982. Cholesterol turnover in lipid phases of human atherosclerotic plaque. J. Lipid Res. 23:733-737.

25. Brown, M. S., and J. L. Goldstein. 1976. Receptor-mediated control of cholesterol metabolism: study of human mutants has disclosed how cells regulate a substance that is both vital and lethal. Science (Wash. DC). 191:150-154.

26. Katz, S. S., D. M. Small, J. G. Brooks, and R. S. Lees. 1976. The physical state of lipids in foam cells of Tangier disease and human fatty streaks. Circulation. 53 and 54(Suppl. II):II-180, 1976.

27. Small, D. M. 1977. Liquid crystals in living and dying systems. J. Colloid Interface Sci. 58:581-602. 
28. Clarkson, T. B., N. D. M. Lehner, W. D. Wagner, R. W. St. Clair, M. G. Bond, and B. C. Bullock. 1979. A study of atherosclerosis regression in Macaca mulatta. I. Design of experiment and lesion induction. Exp. Mol. Pathol. 30:360-385.

29. Wagner, W. D., R. W. St. Clair, and T. B. Clarkson. 1980. A study of atherosclerosis regression in Macaca mulatta. II. Chemical changes in arteries from animals with atherosclerosis induced for 19 months then regressed for 24 months at plasma cholesterol concentrations of 300 or $200 \mathrm{mg} / \mathrm{dl}$. Exp. Mol. Pathol. 32:162-174.

30. Wagner, W. D., R. W. St. Clair, T. B. Clarkson, and W. E. Connor, Jr. 1980. A study of atherosclerosis regression in Macaca mulatta. III. Chemical changes in arteries from animals with atherosclerosis induced for 19 months and regressed for $\mathbf{4 8}$ months at plasma cholesterol concentrations of 300 or $200 \mathrm{mg} / \mathrm{dl}$. Am. J. Pathol. 100:633-650.

31. Clarkson, T. B., M. G. Bond, B. C. Bullock, and C. Marzetta. 1981. A study of atherosclerosis regression in Macaca mulatta. IV. Changes in coronary arteries from animals with atherosclerosis induced for 19 months and then regressed for 24 or 48 months at plasma cho- lesterol concentrations of 300 or $200 \mathrm{mg} / \mathrm{dl}$. Exp. Mol. Pathol. 34:345368.

32. Armstrong, M. L., and M. B. Megan. 1972. Lipid depletion in atheromatous coronary arteries in rhesus monkeys after regression diets. Circ. Res. 30:675-680.

33. DePalma, R. G., E. M. Bellon, S. Koletsky, and D. L. Schneider. 1979. Atherosclerotic plaque regression in rhesus monkeys induced by bile acid sequestrant. Exp. Mol. Pathol. 31:425-439.

34. Kokatnur, M. G., G. T. Malcom, D. A. Eggen, and J. P. Strong. 1975. Depletion of aortic free and ester cholesterol by dietary means in rhesus monkeys with fatty streaks. Atherosclerosis. 21:195-203.

35. Wissler, R. W., and D. Vesselinovitch. 1976. Studies of regression of advanced atherosclerosis in experimental animals and man. Ann. NY Acad. Sci. 275:353-378.

36. Srinivasan, S. R., D. Patton, B. Radakrishnamurthy, T. A. Foster, M. R. Malinow, P. McLaughlin, and G. S. Berenson. 1980. Lipid changes in atherosclerotic aortas of Macaca fascicularis after various regression regimens. Atherosclerosis. 37:596-601. 